\title{
En Bloc Right Hemicolectomy with Pancreaticoduodenectomy for Locally Advanced Right-Sided Colon Cancer
}

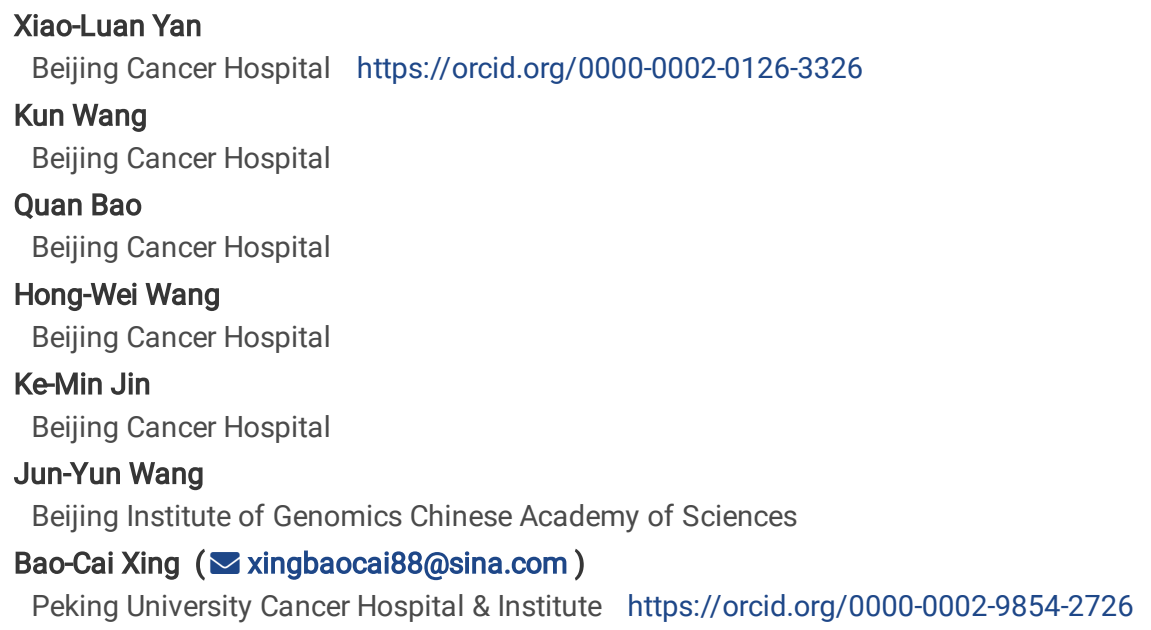




\section{Abstract}

Background: En bloc right hemicolectomy with pancreaticoduodenectomy (RHCPD) is the optimum treatment to achieve the adequate margin of resection (RO) for locally advanced right-sided colon cancer (LARCC). Information regarding the indications and outcomes of this procedure is limited.

Method: In this retrospective study, patients who underwent RHCPD for LARCC during October 2010 to May 2019 were identified. The overall survival (OS), disease-free survival (DFS), mortality, postsurgical complications, gene mutational analysis, and prognostic factors were evaluated. Survival was estimated using Kaplan-Meir method.

Results: Nineteen patients who underwent RHCPD were included in the study. The OS was $88.2 \%, 65.9 \%$, and $57.6 \%$ at 1,3 , and 5 years. The DFS was $71.6 \%, 56.4 \%$, and $56.4 \%$ at 1,3 , and 5 years. The median operative time was 320 minutes (range: $222-410$ minutes), and the median operative blood loss was $268 \mathrm{~mL}$ (range: $100-600 \mathrm{~mL}$ ). The OS was significantly better among patients with well-differentiated tumor $(P=0.03)$, N0 stage $(P=0.01)$, and high microsatellite instability (MSI) $(P=0.047)$ and in patients who received chemotherapy $(P=0.027)$. The major postoperative complications occurred in 8 patients $(42 \%)$, with pancreatic fistula (PF) being the most common. On the basis of the univariate analysis, poorly differentiated tumor, regional lymph node dissemination, MSI status, and no perioperative chemotherapy were the significant predictors of poor survival $(P<0.05)$. By multivariate analysis, only lymph node status was the significant factor (hazard ratio [HR]: 79.045; $P=0.021$ ).

Conclusions: This study suggests that RHCPD is feasible and can achieve complete tumor clearance with favorable outcome, particularly in patients with lymph node-negative status.

\section{Background}

Colorectal cancer (CRC) is the third most common malignancy globally with a high mortality rate at the advanced stages [1-3]. The rate of adjacent organ invasion in CRC is $5.2-23.6 \%[4,5]$. Locally advanced CRC represent about $5-22 \%$ of all CRC, and carcinoma of the right colon invading adjacent viscera is rare (11\%-28\%) [5-7]. Surgical resection is considered as the standard curative treatment for CRC [3]. Incomplete resection and separation of colon cancer from adherent organs are considered leading to tumor recurrence and a poor prognosis [8-10]. En bloc resection is the curative resection for locally advanced CRC that has invaded adjacent structures without distant metastasis. Locally advanced right-sided colon cancer (LARCC) can involve the duodenum, pancreas, and other organs. In this situation, extended or multivisceral resection is necessary to achieve the adequate margin of resection (R0).

En bloc right colectomy with pancreaticoduodenectomy (RHCPD) is the treatment of choice for LARCC to achieve R0 resection [11, 12] and was first reported in 1953 [13]. Despite the complexity of RCD, several studies have reported acceptable morbidity and mortality rate [7, 11, 14]. However, few studies reported the long-term outcome and clinicopathology findings of patients undergoing RHCPD for LARCC [5, 12, 15-18]. In China, there are very limited studies describing the long-term survival and histologic findings of LARCC treated with RHCPD $[5,12,19]$. In addition, there is no study to reveal the potential relationship between the clinical evidence with histologic-genetic status and prognosis. Hence, we report a retrospective study aimed to assess the feasibility of RHCPD in achieving complete tumor clearance with favorable outcome and to identify the influencing factors that affect the prognosis in patients undergoing en bloc RHCPD for LARCC with malignant infiltration into adjacent organs. Pathologic features and gene expression were also studied in these patients.

\section{Methods}

\section{Patient characteristics}

In this retrospective study, patients with primary right-sided colon cancer who underwent radical right colectomy (RC) during October 2010 and May 2019, at the Beijing Cancer Hospital, were included. The patient demographics, duration of surgery, estimated blood loss, tumor pathology, chemotherapy received, morbidity, mortality, and long-term survival were collected. Patients with (1) histologically proven colon carcinoma; (2) no evidence of metastasis disease in preoperative imaging; (3) biopsy-proven T4 cancer either to duodenum or pancreas; and (4) patients who were capable of completing the radiologic follow-up at our institution were included. All the patients underwent potential curative resections. Patients with distant metastasis, local recurrent tumor, or secondary involvement of the duodenum and/or pancreatic head rather than direct infiltrate were excluded. This study was approved by the institutional ethical committee of the Beijing Cancer Hospital, and written informed consent was obtained from all the patients included in the study. All the procedures were performed in accordance with the 1964 Helsinki declaration and its later amendments.

\section{Diagnosis and indications for RHCPD}

Local tumor infiltration was evaluated using preoperative computed tomography (CT). The preoperative carcinoembryonic antigen (CEA) and cancer antigen 19 - 9 (CA19-9) levels were routinely tested in all the patients. Preoperative colonoscopy and histopathologic examination of the tumor were performed for the confirmation of RHCPD. The indications for RHCPD were as follows: (1) preoperative histologic confirmation of colon carcinoma; (2) colon cancer that could not be dissociated from the duodenum and/or pancreas; (3) radical resection feasible on preoperative evaluation without distant metastasis; and (4) patients without severe comorbidity and tolerable to a radical multivisceral excision [5, 16, 17]. 


\section{Surgical procedure for RHCPD \\ Resection}

A Cattell-Brasch maneuver was initially performed followed by an extended Kocher maneuver to mobilize the duodenum fully [14]. The resectability of LARCC and the amount of infiltration into the duodenum and/or pancreas was evaluated after complete mobilization of the right colon and duodenum without dissecting the adherent organs from the cancer. RHCPD was performed after establishment of R0 resection via the standard procedures. Pancreaticoduodenectomy (PD) was undertaken with a pyloric antrectomy in all patients [14, 16]. If the portal vein and/or superior mesenteric vein (SMV) was involved, resection of the mesentericoportal vein and an end-to-end anastomosis were carried out.

\section{Reconstruction}

Reconstruction was performed in accordance with the modified Child's reconstruction method, with an end-to-side pancreaticogastrostomy or pancreaticojejunostomy, depending on the situation of the pancreatic duct. The stent of the pancreatic duct was routinely used in pancreatojejunostomy. Reconstruction of the bowel was performed via stapled side-to-side anastomosis of the ileum and transverse colon. After reconstruction, rubber drains were inserted near the biliary and pancreatic anastomoses, and the abdominal wall wounds were closed [5, 14,16$]$.

\section{Pathology and gene testing}

The tumor stage was assessed as per the classification of American Joint Committee of Cancer (AJCC) [20]. Postoperative complications evaluated includes the presence of pancreatic fistula (PF), delayed gastric emptying (DGE), and intraabdominal abscess. Postoperative PF was categorized according to the International Study Group on Pancreatic Fistula Definition [21, 22]. DGE was defined according to the consensus definition of DGE after pancreatic surgery suggested by the International Study Group of Pancreatic Surgery [23]. Intraabdominal abscess was defined as a pocket of infected fluid and pus located inside the abdominal cavity.

Formalin-fixed, paraffin-embedded blocks was used to determine tumor cellularity. Tumors were macrodissected to remove contaminating normal tissue, resulting in samples containing $>20 \%$ neoplastic cells. Sample preparation, library construction, exome capture, next-generation sequencing (NGS), and bioinformatics analyses of tumor and normal samples were performed at GloriousMed Holdings Co., Ltd. (Pudong New Area, Shanghai). Mutation status of KRAS, NRAS, BRAF, HER2, and HER4 was tested using NGS.

Microsatellite instability (MSI) was assessed using the MSI Analysis System Version 1.2 (Promega, Madison, WI), composed of 5 pseudomonomorphic mononucleotide repeats (BAT-25, BAT-26, NR-21, NR-24, and MONO-27) to detect MSI. More than 2 altered markers of 5 are classified as MSI high (MSI-H).

\section{Follow-up}

All patients were followed up at 3-month intervals during the first 2 postoperative years, then at 6-month intervals during the next 3 years, and at least annually thereafter. During every follow-up, physical examination, CEA, CA19-9 measurement, chest radiography, and abdominal ultrasound or CT were performed. The patients were followed up as per a standard protocol [24]. Patients were followed up via annual colonoscopy examination at outpatient clinics.

\section{Primary and secondary outcomes}

The overall survival (OS) was considered as the primary outcome. The disease-free survival (DFS), 30-day postoperative mortality, postsurgical complications, gene testing, and prognostic factors evaluation were the secondary outcomes.

\section{Statistical analysis}

Numerical data were presented as the median (range). The survival rate was analyzed by the Kaplan-Meier (KM) method. Prognostic variables were examined using univariate analysis, and variables with $P$ value of $<0.1$ were used in the multivariate Cox proportional hazards model to identify independent predictors. $P<0.05$ was considered as statistical significance. Hazard ratio (HR) was reported with $95 \%$ confidence interval (CI). All data were analyzed using SPSS v.16.0 software (SPSS, Chicago, IL).

\section{Results}

\section{Patients characteristics}

Between October 2010 and May 2019, 2269 patients with primary right-sided colon cancer underwent radical RC at the Beijing Cancer Hospital. Among them, 19 patients ( 12 men and 7 women) underwent RHCPD for LARCC with direct infiltration into the duodenum and/or pancreas. The median age of the patients was 60 years (range, 35-75 years). The tumors were located in the ascending colon (3 patients) and hepatic flexure (16 patients). Infiltration of the tumor into the duodenum was observed in all the patients, pancreas in 4 patients, the liver in 2 patients, and the SMV in 1 patient. The median preoperative CEA was $5.73 \mathrm{ng} / \mathrm{mL}$ (range: $0.934-18.53 \mathrm{ng} / \mathrm{mL}$ ), and CA19-9 was 43.19 IU/mL (range: 0.50-228.40 IU/mL). During presentation, 10 patients had anemia, and 8 had abdominal pain. Other prominent symptoms were history of significant weight loss $(n=7)$, abdominal distension ( $n=5)$, and vomiting $(n=5)$. Preoperative chemotherapy of the patients is shown in Table 1. 


\section{Overall survival and disease-free survival}

The median follow-up time was 38.5 moths (range: 5-112 months). During the follow-up period, 6 patients died from abdominal or liver metastases. The mean survival time was 75.78 months ( $95 \% \mathrm{Cl}, 53.3$ : 98.3 ). The $1-, 3-$, and 5 -year OS was $88.2 \%, 65.9 \%$, and $57.6 \%$, and DFS was $71.6 \%, 56.4 \%$, and $56.4 \%$ respectively (Fig. 1 ). Of the 13 patients, 4 survived $>5$ years with no recurrence (Cases $2,3,7$, and 8 ).

On the basis of the KM-survival curves between various groups, the survival was significantly better among patients with well- or moderately differentiated tumor $(P=0.03)$ (Fig. 2A), N0 stage $(P=0.01)$ (Fig. 2B), MSI-H $(P=0.047)($ Fig. $2 \mathrm{C})$ and in patients who received chemotherapy $(P=$ 0.027) (Fig. 2D).

\section{Postoperative complications and treatment}

The treatments and outcomes data of the patients are listed in Table 2. The median operative time was 320 minutes (range: 222-410 minutes), and the median operative blood loss was $268 \mathrm{~mL}$ (range: 100-600 mL). Blood was transfused intraoperatively in 11 patients with an average amount of $2.5 \mathrm{U}$ (range: $2-6 \mathrm{U}$ ). The postoperative hospital stay was 23.5 days (range: $11-45$ days). None of the patients died during the postoperative 30 days.

Major postoperative complications occurred in 8 patients (42\%) with PF being the most common. No patient had DGE, ileocolic, gastrojejunal, or jejunojejunal anastomotic leak. A total of 15 patients received adjuvant chemotherapy, including XELOX (9 patients), FOLFOX4 (1 patients), mFOLFOX6 (1 patient), FOLFIRI (1 patients), Capecitabine (1 patients), FOLFOXIRI + Bevacizumab (1 patients), and XELOX + Bevacizumab + Pembrolizumab (1 patients).

\section{Pathologic findings and genetic testing}

The pathologic findings and genetic testing results are listed in Table 3. Tumors were classified as well-differentiated adenocarcinoma (3 patients), moderately differentiated adenocarcinoma (12 patients), and poorly differentiated adenocarcinoma (4 patients) based on histologic findings. According to the AJCC classification system, 15 patients were N0 staged, 1 as N1b, 2 as N2b, and 1 as N2a. All of the tumors had clear resection margins (R0). In mutation testing, 11 patients were K-Ras mutant, 1 patient was B-Raf V600E mutant, 2 were Her- 2 mutant, and none of the patients were N-Ras mutant as identified by using NGS. A total of 8 patients were identified as MSI-high status.

\section{Prognostic factors for overall survival}

On the basis of the univariate analysis, tumor differentiation, N stage, MSI status, K-Ras, B-Ras, Her-2, and perioperative chemotherapy were the significant prognostic factors $(P<0.05)$. In multivariate analysis, only $\mathrm{N}+$ was a significant independent predictor $(\mathrm{HR}$ : 79.04; $P=0.021)$ of poor survival (Table 4).

\section{Discussion}

Right-sided CRC invading duodenum and/or pancreas is a rare condition [6, 23, 25], and only a few studies have reported adjacent-organ resection [4, 6, 7, 14-16, 25-29]. In our study, among 2269 patients with primary right-sided CRC who underwent radical RC screened, only 19 patients (12 men and 7 women) underwent en bloc RHCPD for LARCC with direct infiltration into the duodenum and/or pancreas. The patients who underwent duodenal resection with correction by direct suture or pedicled ileal flap were excluded because of the poor outcome and high rate of morbidity and mortality [8] LARCC once confirmed during the operation, all adhesions between tumor and adjacent organs should be considered as malignant invasion due to $33-84 \%$ malignant invasion on pathologic examination $[4,15]$ and should not be separated as there exist a risk of tumor recurrence rate of $90-100 \%$ $[9,10]$. In our study, en bloc resection was performed, and adhesions were verified as malignant only after histopathologic examination.

Right-sided CRC invading duodenum and/or pancreas was considered to have poor outcomes and unresectable in the earlier days. However, recent studies have reported a promising prognosis, with a 5-year survival rate ranging from $21-55 \%$ in patients with LARCC invading adjacent organs undergoing en bloc multivisceral resection $[4,5,12,15,19]$. Similarly, in our study, all the patients who underwent curative RHCPD achieved good outcomes, with $1-, 3-$, and 5 -year OS rate of $88.2 \%, 65.9 \%$, and $57.6 \%$, whereas DFS rates of $71.6 \%, 56.4 \%$, and $56.4 \%$ respectively. Comparatively higher OS rate in our study is probably because of the fact that even though all the patients were staged T4b, regional lymph node dissemination of the cancer may not be that advanced because only 5 out of 19 patients were lymph node positive (N2a and N1b). In addition, some colon cancers exhibits locally aggressive invasion instead of distant spread [4, 15, 27, 29]. According to the previous reports, 25-60\% of right colon carcinoma that invaded the adjacent duodenum or pancreas do not have lymph node metastasis $[4,6,15,27,29]$. Furthermore, Saiura et al reported significantly longer survival in patients with node-negative status than node-positive patients [15]. Similarly, in our study, the survival of patients with node-positive had short survival (<3 years) at the time of last follow-up Meanwhile, the 3-and 5-year OS of 14 patients with N0 were $88.9 \%$ and $77.8 \%$, respectively, among them 4 patients survived for $>5$ years. In subsequent univariate and multivariate analysis, regional lymph node dissemination was significant prognostic factor for poor survival.

Furthermore, based on the KM curve analysis, OS was significantly better in patients with well- or moderately differentiated tumor compared with patients with poorly differentiated tumor. This is probably because of the fact that the histologic type of tumor may affect the lymph node metastasis and prognosis in patients with LARCC as reported by a retrospective study conducted by Saiura et al 2008. The rate of lymph node metastasis was significantly higher in well-differentiated adenocarcinoma than mucinous or poorly differentiated adenocarcinoma in LARCC $(P=0.015)$ [15]. In our 
study, only 1 patient (6.7\%) with moderately differentiated adenocarcinoma had node-positive status, whereas all the patients with poorly differentiation adenocarcinoma had node-positive status, and the 3-year OS rates of the 2 groups (well- or moderately differentiated tumor vs. poorly differentiation adenocarcinoma) were $82.1 \%$ versus $0 \%$.

Molecular markers such as K-Ras, N-Ras, B-Raf, HER2, and MSI play a significant role in the disease prognosis in CRC, and hence, analysis of these biomarkers helps in facilitating proper treatment to the needy patients [30]. In our study, all the patients in MSI-H status survived for $>3$ years, while 3year OS of patients in MSS status was only 35.0\% $(P=0.047)$. OS did not differ significantly between K-Ras mutant and wild-type $(P=0.888)$, BRAF V600E mutant and wild-type tumors $(P=0.771)$ nor Her-2 $(P=0.635)$. Hence, only MSI was the significant prognostic factor affecting survival.

In FOXTROT trial, preoperative chemotherapy has resulted in significant downstaging of tumor in patients with locally advanced colon cancer compared to postoperative chemotherapy $(P=0.04)$ [31]. Another retrospective study by Arredondo et al. has also shown tumor downstaging (62.5\%), $\mathrm{R} 0$ resection (100\%), and a promising prognosis (median OS of 31 months) in locally advanced colon cancer patients treated with preoperative chemotherapy [32]. Similarly, in our study, the 3-year OS rates was greater in the preoperative and postoperative chemotherapy group (100\% and $77.8 \%$ ) compared with no perioperative chemotherapy group (25.0\%). However, these finding need to be confirmed by considering studies with large sample size.

There are several limitations associated with the present study. First, the number of LARCC patients with invasion of duodenum and/or pancreas is low, and hence, the number of participants is small in this study. Large-scale studies may produce more reliable results. Second, the chemotherapy regimens varied among patients. In the era of advanced chemotherapy, administering the same regimen for a long-term study seems formidable. However, the present study also has several strengths such as this study gathered the largest number of patients, and all the clinical information and follow-up were proved to be accurate. Moreover, histologic-genetic examination was performed in detail, and we were able to build a bridge between the preoperative clinical evidence with histologic-genetic findings and prognosis.

\section{Conclusions}

En bloc RHCPD may result in long-term survival in patients having LARCC with infiltrated adjacent organs. This aggressive approach may help improve the prognosis, particularly in patients with node-negative status. This study also evaluated the prognostic factors for OS and the role of mutational status of several genes on disease prognosis. Long-term and larger-scale studies may produce more reliable results.

\section{Abbreviations}

AJCC American Joint Committee of Cancer

Cl Confidence interval

CRC Colorectal cancer

CEA Carcinoembryonic antigen

CA19-9 cancer antigen $19-9$

CT Computed tomography

DFS Disease-free survival

DGE Delayed gastric emptying

HR Hazard ratio

LARCC Locally advanced right-sided colon cancer

MSI Microsatellite instability

NGS Next-generation sequencing

OS Overall survival

PF Pancreatic fistula

RHCPD Right hemicolectomy with pancreaticoduodenectomy

RC Right colectomy

SMV Superior mesenteric vein 


\section{Declarations}

\section{Ethics approval and consent to participate}

This study was approved by the institutional ethical committee of the Beijing Cancer Hospital, and written informed consent was obtained from all the patients included in the study. All the procedures were performed in accordance with the 1964 Helsinki declaration and its later amendments.

\section{Consent for publication}

Written informed consent for publication was obtained from all participants.

\section{Availability of data and material}

All data generated or analysed during this study are included in this published article.

\section{Competing interests}

The authors declare that they have no competing interests.

\section{Funding}

This study was supported by grants (No.81874143, No.31971192) from the National Natural Science Foundation of China and Beijing Natrual Science Foundation (No.7192035).

\section{Authors contributions.}

XLY proposed the study, collected and analyzed the data, and wrote the first draft. All authors contributed to the design and interpretation of the study and to further drafts. BCX is the guarantor. All authors have read and approved the manuscript.

\section{Acknowledgements}

The authors would like to thank Dr. Ming Liu, Dr. Wei Liu, Dr. Li-Jun Wang, and Dr. Da Xu for their operative support.

Medical writing support was provided by Dr. Vedashree S and Dr Amit Bhat, Indegene Pvt. Ltd., Bangalore, India.

\section{References}

1. Bray F, Ferlay J, Soerjomataram I, Siegel RL, Torre LA, Jemal A. Global cancer statistics 2018: GLOBOCAN estimates of incidence and mortality worldwide for 36 cancers in 185 countries. CA Cancer J Clin. 2018;68:394-424. https://doi.org/10.3322/caac.21492.

2. Baran B, Mert Ozupek N, Yerli Tetik N, Acar E, Bekcioglu O, Baskin Y. Difference Between Left-Sided and Right-Sided Colorectal Cancer: A Focused Review of Literature. Gastroenterol Res. 2018;11:264-73. https://doi.org/10.14740/gr1062w.

3. IGUCHI K, MUSHIAKE H, AOYAMA T, SUWA H, YUKAWA N. OTA M, et al. Additional Surgical Resection After Endoscopic Resection for Patients With High-risk T1 Colorectal Cancer. In Vivo. 2019;33:1243-8. https://doi.org/10.21873/invivo.11596.

4. Kapoor S, Das B, Pal S, Sahni P, Chattopadhyay TK. En bloc resection of right-sided colonic adenocarcinoma with adjacent organ invasion. Int J Colorectal Dis. 2006;21:265-8. https://doi.org/10.1007/s00384-005-0756-z.

5. Zhang J, Leng J, Qian H, Qiu H, Wu J, Liu B, et al. En bloc pancreaticoduodenectomy and right colectomy in the treatment of locally advanced colon cancer. Dis Colon Rectum. 2013;56:874-80. https://doi.org/10.1097/DCR.0b013e3182941704.

6. Fuks D, Pessaux P, Tuech J-J, Mauvais F, Bréhant O, Dumont F, et al. Management of patients with carcinoma of the right colon invading the duodenum or pancreatic head. Int J Colorectal Dis. 2008;23:477-81. https://doi.org/10.1007/s00384-007-0409-5.

7. Lee W-S, Lee WY, Chun H-K, Choi S-H. En bloc Resection for Right Colon Cancer Directly Invading Duodenum or Pancreatic Head. Yonsei Med J. 2009;50:803-6. https://doi.org/10.3349/ymj.2009.50.6.803.

8. Cirocchi R, Partelli S, Castellani E, Renzi C, Parisi A, Noya G, et al. Right hemicolectomy plus pancreaticoduodenectomy vs partial duodenectomy in treatment of locally advanced right colon cancer invading pancreas and/or only duodenum. Surg Oncol. 2014;23:92-8. https://doi.org/10.1016/j.suronc.2014.03.003.

9. Perez RO, Coser RB, Kiss DR, Iwashita RA, Jukemura J, Cunha JEM, et al. Combined resection of the duodenum and pancreas for locally advanced colon cancer. Curr Surg. 2005;62:613-7. https://doi.org/10.1016/j.cursur.2005.03.021.

10. Hunter JA, Ryan JA, Schultz P. En bloc resection of colon cancer adherent to other organs. Am J Surg. 1987;154:67-71. https://doi.org/10.1016/0002-9610(87)90292-3.

11. Noda H, Kato T, Kamiyama H, Toyama N, Konishi F. En bloc right hemicolectomy and pancreaticoduodenectomy with superior mesenteric vein resection for advanced right-sided colon cancer. Clin J Gastroenterol. 2010;3:259-61. https://doi.org/10.1007/s12328-010-0175-8. 
12. Li D, Si X, Wan T, Zhou Y. A pooled analysis of en bloc right hemicolectomy with pancreaticoduodenectomy for locally advanced right-sided colon cancer. Int J Colorectal Dis. 2018;33:819-22. https://doi.org/10.1007/s00384-018-2997-7.

13. Van Prohaska J, Govostis MC, Wasick M. Multiple organ resection for advanced carcinoma of the colon and rectum. Surg Gynecol Obstet. 1953;97:177-82.

14. Kimchi ET, Nikfarjam M, Gusani NJ, Avella DM, Staveley-O'Carroll KF. Combined pancreaticoduodenectomy and extended right hemicolectomy: outcomes and indications. HPB. 2009;11:559-64. https://doi.org/10.1111/j.1477-2574.2009.00087.x.

15. Saiura A, Yamamoto J, Ueno M, Koga R, Seki M, Kokudo N. Long-Term Survival in Patients with Locally Advanced Colon Cancer After En Bloc Pancreaticoduodenectomy and Colectomy. Dis Colon Rectum. 2008;51:1548-51. https://doi.org/10.1007/s10350-008-9318-0.

16. Kaneda Y, Noda H, Endo Y, Kakizawa N, Ichida K, Watanabe F, et al. En bloc pancreaticoduodenectomy and right hemicolectomy for locally advanced right-sided colon cancer. World J Gastrointest Oncol. 2017;9:372-8. https://doi.org/10.4251/wjgo.v9.i9.372.

17. Sheng Q-S, Chen W-B, Li M-J, Cheng X-B, Wang W-B, Lin J-J. Combined right hemicolectomy and pancreaticoduodenectomy for locally advanced right hemicolon cancer. Hepatobiliary Pancreat Dis Int. 2015;14:320-4. https://doi.org/10.1016/S1499-3872(15)60374-5.

18. Ağalar C, Canda AE, Unek T, Sokmen S. En Bloc Pancreaticoduodenectomy for Locally Advanced Right Colon Cancers. Int J Surg Oncol. 2017. https://doi.org/10.1155/2017/5179686.

19. Zhao Y, Han G, Lu C, Ren Y, Li J, Ma P, et al. Right hemicolectomy and multivisceral resection of right colon cancer: A report of 21 cases. J Huazhong Univ Sci Technolog Med Sci. 2015;35:255-8. https://doi.org/10.1007/s11596-015-1420-7.

20. Edge SB, Compton CC. The American Joint Committee on Cancer: the 7th edition of the AJCC cancer staging manual and the future of TNM. Ann Surg Oncol. 2010;17:1471-4. https://doi.org/10.1245/s10434-010-0985-4.

21. Bassi C, Dervenis C, Butturini G, Fingerhut A, Yeo C, Izbicki J, et al. Postoperative pancreatic fistula: an international study group (ISGPF) definition. Surgery. 2005;138:8-13. https://doi.org/10.1016/j.surg.2005.05.001.

22. Bassi C, Marchegiani G, Dervenis C, Sarr M, Abu Hilal M, Adham M, et al. The 2016 update of the International Study Group (ISGPS) definition and grading of postoperative pancreatic fistula: 11 Years After. Surgery. 2017;161:584-91. https://doi.org/10.1016/j.surg.2016.11.014.

23. Wente MN, Bassi C, Dervenis C, Fingerhut A, Gouma DJ, Izbicki JR, et al. Delayed gastric emptying (DGE) after pancreatic surgery: a suggested definition by the International Study Group of Pancreatic Surgery (ISGPS). Surgery. 2007;142:761-8. https://doi.org/10.1016/j.surg.2007.05.005.

24. Yun SH, Yun HR, Lee WS, Cho YB, Lee WY, Chun HK. The clinical outcome and prognostic factors after multi-visceral resection for advanced colon cancer. Eur J Surg Oncol J Eur Soc Surg Oncol Br Assoc Surg Oncol. 2009;35:721-7. https://doi.org/10.1016/j.ejso.2008.01.024.

25. Song X, Wang L, Zhan W, Wang J, He Y, Lian L, et al. Right hemicolectomy combined with pancreatico- duodenectomy for the treatment of colon carcinoma invading the duodenum or pancreas. Chin Med J (Engl). 2006;119:1740-3.

26. Lianwen Y, Jianping Z, Guoshun S, Dongcai L, Jiapeng Z. Surgical treatment for right colon cancer directly invading the duodenum. Am Surg. 2009;75:385-8.

27. Koea JB, Conlon K, Paty PB, Guillem JG, Cohen AM. Pancreatic or duodenal resection or both for advanced carcinoma of the right colon: Is it justified? Dis Colon Rectum. 2000;43:460-5. https://doi.org/10.1007/BF02237187.

28. Harrison LE, Merchant N, Cohen AM, Brennan MF. Pancreaticoduodenectomy for nonperiampullary primary tumors. Am J Surg. 1997;174:393-5. https://doi.org/10.1016/S0002-9610(97)00121-9.

29. Curley SA, Evans DB, Ames FC. Resection for cure of carcinoma of the colon directly invading the duodenum or pancreatic head. J Am Coll Surg. 1994;179:587-92.

30. Afrăsânie V-A, Marinca MV, Alexa-Stratulat T, Gafton B, Păduraru M, Adavidoaiei AM, et al. KRAS, NRAS, BRAF, HER2 and Microsatellite Instability in Metastatic Colorectal Cancer - Practical Implications for the Clinician. Radiol Oncol. 2019;53:265-74. https://doi.org/10.2478/raon-20190033.

31. FOXTROT Collaborative Group. Feasibility of preoperative chemotherapy for locally advanced, operable colon cancer: the pilot phase of a randomised controlled trial. Lancet Oncol. 2012;13:1152-60. https://doi.org/10.1016/S1470-2045(12)70348-0.

32. Arredondo J, Martínez P, Baixauli J, Pastor C, Rodríguez J, Pardo F, et al. Analysis of surgical complications of primary tumor resection after neoadjuvant treatment in stage IV colon cancer. J Gastrointest Oncol. 2014;5:148-53.

\section{Tables}

Table 1. Demographic and Clinical Characteristics of the Study Patients With LARCC 


\begin{tabular}{|c|c|c|c|c|c|c|c|c|}
\hline Case & Gender & $\begin{array}{l}\text { Age } \\
\text { (Years) }\end{array}$ & $\begin{array}{l}\text { Site of } \\
\text { Colon } \\
\text { cancer }\end{array}$ & $\begin{array}{l}\text { Adjacent Organ Infiltration } \\
\text { on Preoperative CT }\end{array}$ & $\begin{array}{l}\text { Preoperative } \\
\text { CEA (ng/mL) }\end{array}$ & $\begin{array}{l}\text { Preoperative } \\
\text { CA19-9 } \\
\text { (IU/mL) }\end{array}$ & Comorbidity & $\begin{array}{l}\text { Preoperative } \\
\text { Therapy }\end{array}$ \\
\hline 1 & $M$ & 48 & ASC & $\mathrm{Du}+\mathrm{Pa}$ & 5.04 & 86.45 & - & - \\
\hline 2 & $\mathrm{~F}$ & 44 & $\mathrm{HF}$ & $\mathrm{Du}+\mathrm{Pa}+\mathrm{SMV}$ & 7.65 & 228.40 & - & FOLFOX4 \\
\hline 3 & $M$ & 48 & $\mathrm{HF}$ & $\mathrm{Du}+\mathrm{L}$ & 14.58 & 2.78 & - & - \\
\hline 4 & M & 60 & $\mathrm{HF}$ & $\mathrm{Du}$ & 6.22 & 28.59 & A & - \\
\hline 5 & $M$ & 75 & $\mathrm{HF}$ & $\mathrm{Du}$ & 4.38 & 118.50 & A & - \\
\hline 6 & M & 62 & ASC & $\mathrm{Du}$ & 3.98 & 192.20 & A & - \\
\hline 7 & $\mathrm{~F}$ & 36 & $\mathrm{HF}$ & $\mathrm{Du}$ & 0.93 & 12.13 & $\mathrm{H}$ & mFOLFOX6 \\
\hline 8 & $\mathrm{~F}$ & 65 & $\mathrm{HF}$ & $\mathrm{Du}$ & 6.01 & 3.36 & HT & - \\
\hline 9 & M & 45 & $\mathrm{HF}$ & $\mathrm{Du}$ & 2.10 & 10.77 & A & - \\
\hline 10 & M & 73 & $\mathrm{HF}$ & $\mathrm{Du}$ & 1.53 & 11.04 & A & - \\
\hline 11 & M & 35 & $\mathrm{HF}$ & $\mathrm{Du}$ & 16.60 & 5.43 & A & - \\
\hline 12 & M & 65 & $\mathrm{HF}$ & $\mathrm{Du}+\mathrm{Pa}$ & 1.62 & 0.60 & - & - \\
\hline 13 & $\mathrm{~F}$ & 46 & $\mathrm{HF}$ & $\mathrm{Du}$ & 6.05 & 59.74 & - & - \\
\hline 14 & $M$ & 54 & $\mathrm{HF}$ & Du+L & 4.96 & 11.56 & A & FOLFOXIRI+BEV \\
\hline 15 & M & 63 & ASC & $\mathrm{Du}$ & 2.41 & 12.69 & - & - \\
\hline 16 & $\mathrm{~F}$ & 42 & $\mathrm{HF}$ & $\mathrm{Du}+\mathrm{Pa}$ & 2.27 & 15.87 & A & XELOX+BEV+Pem \\
\hline 17 & M & 64 & HF & Du & 2.26 & 18.46 & A & - \\
\hline 18 & $\mathrm{~F}$ & 66 & $\mathrm{HF}$ & $\mathrm{Du}$ & 18.53 & 0.50 & A & - \\
\hline 19 & $\mathrm{~F}$ & 65 & $\mathrm{HF}$ & $\mathrm{Du}$ & 1.81 & 2.72 & HT & - \\
\hline
\end{tabular}

A, Aanemia; ASC, ascending colon; BEV, bevacizumab; Du, duodenum; FOLFIRI, folinic acid, fluorouracil, plus irinotecan hydrochloride; FOLFOX, folinic acid, fluorouracil, plus oxaliplatin; $H$, hepatitis; HF, hepatic flexure; $H T$, hypertension; L, liver; m, modified; $M$, male; F, female; Pa: pancreas; Pem, pembrolizumab; SMV, superior mesenteric vein; XELOX, capecitabine plus oxaliplatin;

Table 2. Treatments and survival outcomes in the study patients 


\begin{tabular}{|c|c|c|c|c|c|c|c|c|c|c|}
\hline Case & Operation & $\begin{array}{l}\text { Operative } \\
\text { Time } \\
\text { (Minutes) }\end{array}$ & $\begin{array}{l}\mathrm{OBL} \\
(\mathrm{mL})\end{array}$ & $\begin{array}{l}\text { Blood } \\
\text { Transfusion } \\
\text { (IU) }\end{array}$ & $\begin{array}{l}\text { LOS } \\
\text { (Days) }\end{array}$ & Complications & Adjuvant Therapy & $\begin{array}{l}\text { Survival } \\
\text { (Months) }\end{array}$ & Status & $\begin{array}{l}\text { Cause of } \\
\text { Death }\end{array}$ \\
\hline 1 & RHCPD & 410 & 400 & 4 & 18 & $\mathrm{PF}(\mathrm{C}), \mathrm{IAA}$ & - & 35 & Dead & Recurrence \\
\hline 2 & RHCPD+SMVR & 325 & 300 & - & 18 & - & Capecitabine & 112 & Alive & \\
\hline 3 & RHCPD & 315 & 500 & 4 & 22 & $P F(B), I A A$ & mFOLFOX6 & 103 & Alive & \\
\hline 4 & RHCPD & 345 & 300 & 2 & 45 & IB & - & 16 & Dead & Recurrence \\
\hline 5 & RHCPD & 390 & 400 & 6 & 26 & PF(B), IAA & - & 36 & Dead & Recurrence \\
\hline 6 & RHCPD & 360 & 200 & - & 21 & $\mathrm{PF}(\mathrm{A})$ & XELOX & 9 & Dead & Recurrence \\
\hline 7 & RHCPD & 390 & 100 & - & 15 & - & FOLFIRI & 69 & Alive & \\
\hline 8 & RHCPD & 300 & 400 & - & 16 & $\mathrm{PF}(\mathrm{A})$ & XELOX & 63 & Alive & \\
\hline 9 & RHCPD & 365 & 300 & 4 & 21 & PF(B), IAA & FOLFOX4 & 9 & Dead & Recurrence \\
\hline 10 & RHCPD & 290 & 200 & 4 & 36 & BF & - & 41 & Dead & Recurrence \\
\hline 11 & RHCPD & 284 & 100 & - & 15 & $\mathrm{PF}(\mathrm{A})$ & XELOX & 48 & Alive & \\
\hline 12 & RHCPD & 287 & 100 & - & 26 & $\mathrm{PF}(\mathrm{A})$ & XELOX & 47 & Alive & \\
\hline 13 & RHCPD & 321 & 200 & - & 20 & $B F, I A A$ & XELOX & 41 & Alive & \\
\hline 14 & RHCPD & 330 & 600 & 6 & 43 & ileus & FOLFOXIRI+BEV & 30 & Alive & \\
\hline 15 & RHCPD & 222 & 100 & - & 26 & - & XELOX & 23 & Alive & \\
\hline 16 & RHCPD & 330 & 200 & 4 & 24 & $\operatorname{PF}(\mathrm{A})$ & XELOX+BEV+Pem & 20 & Alive & \\
\hline 17 & RHCPD & 261 & 200 & 4 & 11 & - & XELOX & 17 & Alive & \\
\hline 18 & RHCPD & 315 & 300 & 6 & 25 & $\operatorname{PF}(\mathrm{A})$ & XELOX & 8 & Alive & \\
\hline 19 & RHCPD & 240 & 200 & 4 & 13 & - & XELOX & 5 & Alive & \\
\hline
\end{tabular}

BEV, bevacizumab; BF, biliary fistula; FOLFIRI, folinic acid, fluorouracil, plus irinotecan hydrochloride; FOLFOX, folinic acid, fluorouracil, plus oxaliplatin; IAA, intraabdominal abscess; IB, intraabdominal bleeding; LOS, length of stay; m, modified; OBL, operative blood loss; Pem, pembrolizumab; PF, pancreatic fistula; RHCPD, right hemicolectomy with pancreaticoduodenectomy; SMVR, superior mesenteric vein resection; XELOX, capecitabine plus oxaliplatin

Table 3. PATHOLOGIC FINDINGS and Genetic Testing in the Study Patients 


\begin{tabular}{|c|c|c|c|c|c|c|c|c|c|}
\hline \multirow[t]{2}{*}{ Patients } & \multicolumn{4}{|l|}{ Pathologic Findings } & \multicolumn{5}{|c|}{ Genetic Testing } \\
\hline & Tumor differentiation & $\mathrm{T}$ & $\mathbf{N}$ & $M$ & KRAS & NRAS & BRAF & Her-2 & MSI \\
\hline 1 & Wel & $4 b$ & 0 & 0 & Mutant & W & W & W & MSS \\
\hline 2 & Mod & $4 b$ & 0 & 0 & Mutant & W & W & W & MSI-H \\
\hline 3 & Mod & $4 b$ & 0 & 0 & W & W & W & W & $\mathrm{MSI}-\mathrm{H}$ \\
\hline 4 & $\mathrm{P}$ & $4 b$ & $2 b$ & 0 & Mutant & W & W & W & MSS \\
\hline 5 & $\mathrm{P}$ & $4 b$ & $2 a$ & 0 & Mutant & W & W & W & MSS \\
\hline 6 & $\mathrm{P}$ & $4 b$ & $1 b$ & 0 & W & W & W & W & MSS \\
\hline 7 & Mod & $4 b$ & 0 & 0 & Mutant & W & W & W & MSI-H \\
\hline 8 & Mod & $4 b$ & 0 & 0 & Mutant & W & W & Mutant & MSI-H \\
\hline 9 & Mod & $4 b$ & $1 b$ & 0 & W & W & W & Mutant & MSS \\
\hline 10 & Mod & $4 b$ & 0 & 0 & Mutant & W & W & W & MSI-H \\
\hline 11 & Mod & $4 b$ & 0 & 0 & W & W & W & W & MSS \\
\hline 12 & Mod & $4 b$ & 0 & 0 & W & W & W & W & $\mathrm{MSI}-\mathrm{H}$ \\
\hline 13 & Mod & $4 b$ & 0 & 0 & Mutant & W & W & W & MSS \\
\hline 14 & Mod & $4 b$ & 0 & 0 & W & W & Mutant & W & MSI-H \\
\hline 15 & Wel & $4 b$ & 0 & 0 & Mutant & W & W & W & MSS \\
\hline 16 & Mod & $4 b$ & 0 & 0 & W & W & W & W & MSS \\
\hline 17 & $P$ & $4 b$ & $2 b$ & 0 & Mutant & W & W & W & MSS \\
\hline 18 & Mod & $4 b$ & 0 & 0 & W & W & W & W & MSI-H \\
\hline 19 & Wel & $4 b$ & 0 & 0 & Mutant & W & W & W & MSS \\
\hline
\end{tabular}

MSS, microsatellite stable; MSI-H, microsatellite instability-high; Mod, moderately differentiated; P, poorly differentiated; wel, well-differentiated; W, wildtype

Table 4. Uni- or Multivariate Analyses of Factors Associated With Overall Survival

\begin{tabular}{|c|c|c|c|c|}
\hline Prognostic Factors & & Univariable P & Multivariable analysis HR (95\% Cl) & Multivariable $\mathrm{P}$ \\
\hline Age, years & $<60 / \geq 60$ & 0.340 & & \\
\hline Gender & Male/Female & 0.900 & & \\
\hline Preoperative CEA & $\nabla 5 \mathrm{ng} / \mathrm{mL} / \geq 5 \mathrm{ng} / \mathrm{mL}$ & 0.877 & & \\
\hline Preoperative CA19-9 & $\llbracket 37 \mathrm{kU} / \mathrm{L} / \geq 37 \mathrm{kU} / \mathrm{L}$ & 0.646 & & \\
\hline Operative time & $\llbracket 320$ minutes $/ \geq 320$ minutes & 0.509 & & \\
\hline Operative blood loss & $\otimes 400 \mathrm{~mL} / \geq 400 \mathrm{~mL}$ & 0.933 & & \\
\hline Major complications $\#$ & I/II-IV & 0.748 & & \\
\hline Tumor differentiation & Poorly/Well+Moderately & 0.030 & $0.037 \rrbracket 0.001-1.610 \rrbracket$ & 0.087 \\
\hline $\mathrm{N}$ stage & $\mathrm{NO} / \mathrm{N}+$ & 0.010 & $79.045(1.951-3202.131)$ & 0.021 \\
\hline MSI status & MSI-H/MSS & 0.047 & $0.283 \rrbracket 0.013-6.173 \rrbracket$ & 0.422 \\
\hline K-Ras & Wild/Mutant & 0.888 & & \\
\hline B-Raf & Wild/Mutant & 0.771 & & \\
\hline Her-2 & Wild/Mutant & 0.635 & & \\
\hline Perioperative chemotherapy & Yes/No & 0.027 & $3.076(0.797-11.867)$ & 0.103 \\
\hline
\end{tabular}

CEA, Carcinoembryonic antigen; CA19-9, cancer antigen 19-9; MSI-H, microsatellite instability-high; MSS, microsatellite stable 
Figures

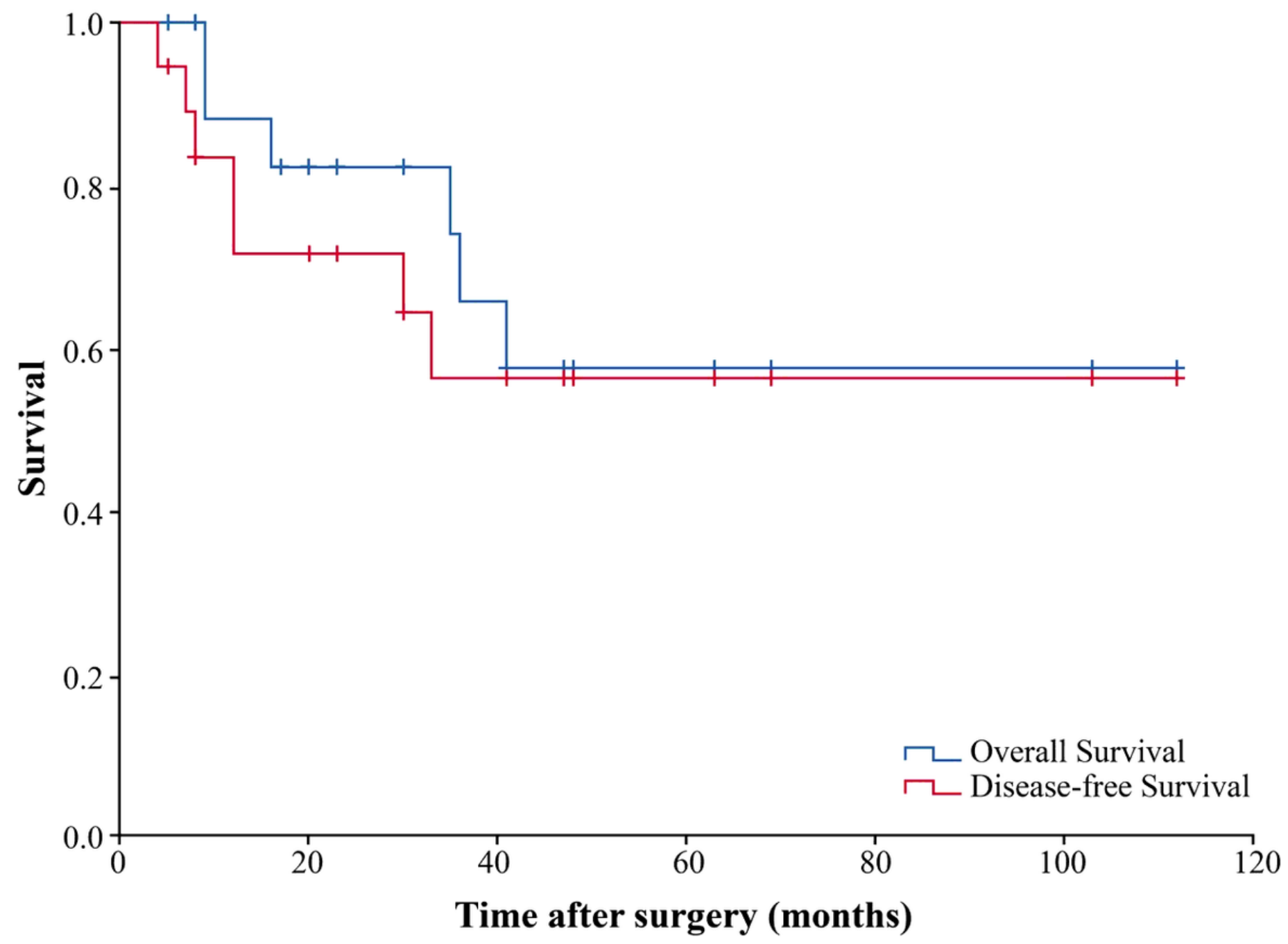

Figure 1

Overall Survival and Disease-Free Survival in Overall Patients 

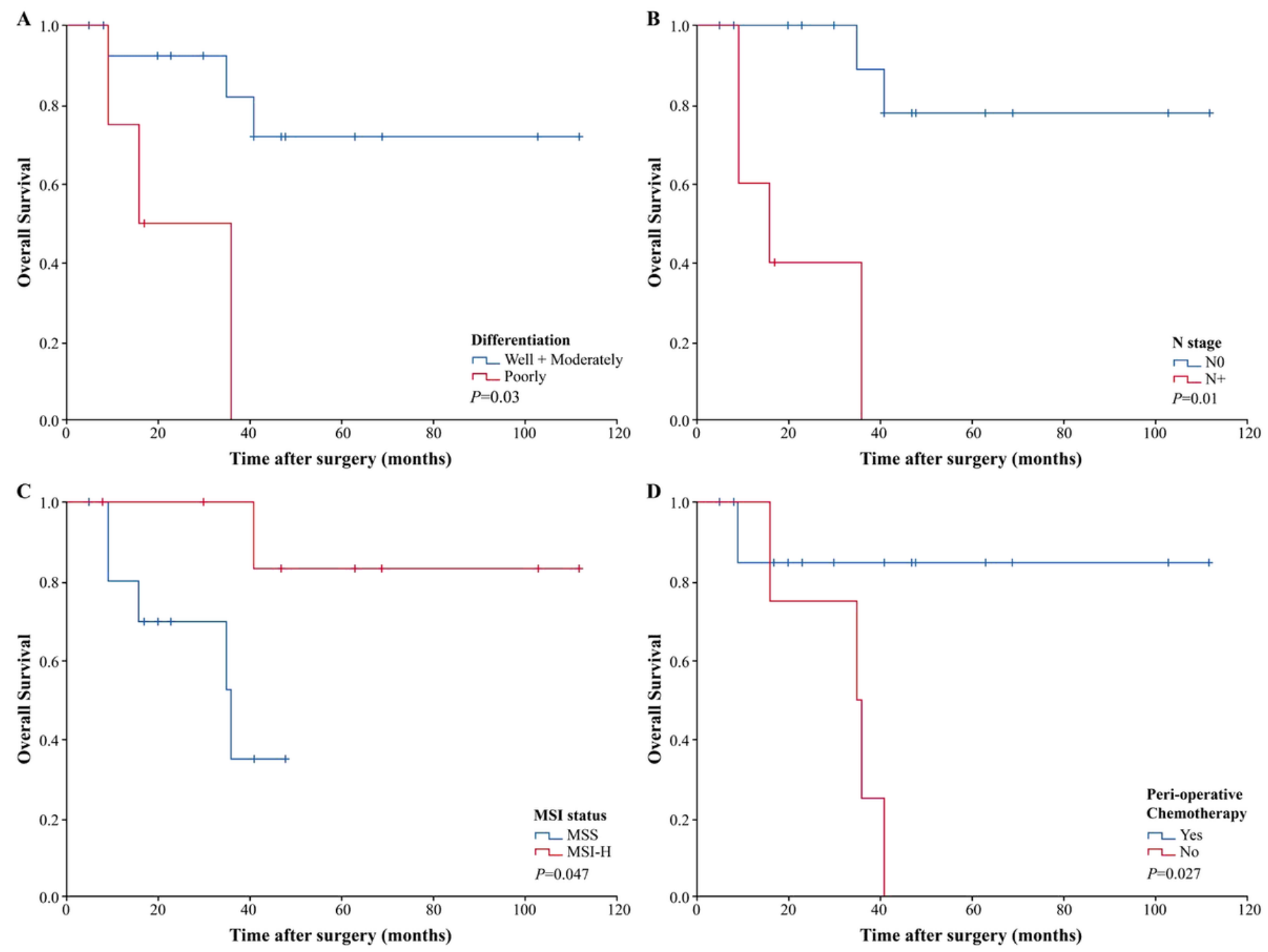

Figure 2

Overall Survival KM Curves in Patients of Various Groups A. Patients with well- or moderately differentiated tumor versus poorly differentiated tumor B. Patients with NO stage versus N+ stage C. Patients with MSS versus MSI-H D. Patients with perioperative chemotherapy versus no chemotherapy MSI$\mathrm{H}$, microsatellite instability-high; MSS, microsatellite stable 